JHR

33,2

Received 13 July 2018 Revised 10 September 2018 Accepted 5 October 2018

\section{Conditions of caring for the elderly and family caregiver stress in Chiang Mai, Thailand}

\author{
Decha Tamdee \\ Faculty of Nursing, Chiang Mai University, Chiang Mai, Thailand \\ Patrapan Tamdee \\ Faculty of Social Sciences, Kasetsart University, Bangkok, Thailand \\ Chieko Greiner \\ Graduate School of Health Sciences, Kobe University, Kobe, Japan \\ Waraporn Boonchiang \\ Faculty of Public Health, Chiang Mai University, Chiang Mai, Thailand \\ Nahoko Okamoto \\ Faculty of Human Sciences, Sophia University, Chiyoda-ku, Japan, and \\ Tokiko Isowa \\ School of Medicine, Mie University, Tsu, Japan
}

Keywords Elderly, Family caregiver, Chiang Mai

Paper type Research paper

(C) Decha Tamdee, Patrapan Tamdee, Chieko Greiner, Waraporn Boonchiang, Nahoko Okamoto and Tokiko Isowa. Published in Journal of Health Research. Published by Emerald Publishing Limited. This article is published under the Creative Commons Attribution (CC BY 4.0) licence. Anyone may reproduce, distribute, translate and create derivative works of this article (for both commercial and non-commercial purposes), subject to full attribution to the original publication and authors. The full terms of this licence may be seen at http://creativecommons.org/licences/by/4.0/legalcode

This study was a part of the research project entitled "International comparison survey on caring for elderly people at home" which the Faculty of Nursing, Chiang Mai University has received cooperation and scholarship from the Graduate School of Health Sciences, Kobe University, Japan. The researcher team would like to take this opportunity to extend our thanks to supporters, the elderly, and community representatives for their collaboration in this research project.

\begin{abstract}
Purpose - The family caregivers play an important role in the good quality of life for the elderly, but most of
Abstract
Purpose - The family caregivers play an important role in the good quality of life for the elderly, but most of them can easily have an emotional and psychological effect on caregiving. The purpose of this paper is to explore the correlation between conditions of caring for the elderly in the family and caregiver stress in a community setting, Chiang Mai Province, Thailand.

Design/methodology/approach - A cross-sectional exploratory descriptive research was conducted in Ban Klang Subdistrict, San Pa Tong District, Chiang Mai Province. Simple random sampling was used to collect data by using a structured interview via a questionnaire with 103 elderly caregivers. The $\chi^{2}$ test was used to explain the conditions related to stress as being a caregiver.

Findings - Most of the caregivers were female and still in good health, but at the same time, underwent little stress. However, they did not receive any training beforehand for taking care of the elderly but mainly done by experience, relationship and gratitude. The conditions correlated with stress as being a caregiver were health status of caregivers, confidence of care, the relationship between caregiver and elderly person, and economic burden of care.

Originality/value - A necessary resource such as body of knowledge in elderly caregiving, long-term care system at the community level and social support from family and intimate persons will encourage confidence in taking care of the elderly in the family and also relieve caregivers' stress.
\end{abstract}

Journal of Health Research Vol. 33 No. 2, 2019 pp. $138-150$ Emerald Publishing Limited 2586-940X DOI 10.1108/JHR-07-2018-0053 


\section{Introduction}

In 2015, Thailand was considered to be an aged society, ranking second after Singapore among the ASEAN member countries due to the dramatic change of population structure in Thailand during 3-4 decades, and six years from 2015, Thailand will be a complete aged society $[1,2]$. Caregiving for the elderly nowadays not only focuses on medical care but also needs to cover emotional support and stimulates active ageing for the elderly[3]. Caregiving for the elderly in Thailand needs to be operated and delivered by family and community because living with their family in the primary community and familiar surroundings as well as receiving support from their family would produce better results for the elderly[2, 4, 5]. Since Thai society upholds values of gratefulness, and considers care and assistance provided for the elderly in their daily lives to be the duty of their children in the family[6] by having their descendants, spouse and relatives take primary responsibility in caring for the elderly[7], so increasing capacity in various aspects for family members caring for the elderly is needed, especially the importance should be placed on the elderly caregivers[8].

The caregivers have a duty to help and support the elderly to enjoy their daily lives, but on the other hand, most of them are likely to be physically and mentally affected, causing the more negative outcome to their quality of life than to other family members $[9,10]$. Because these caregivers can easily have emotional and psychological stress, the feelings of worry, confusion and boredom with caregiving as well as the lack of accurate knowledge of guidelines to caring for the elderly[11] may cause them to lack confidence and worry about caregiving, especially those who have to care for the elderly with depression, dementia and Alzheimer symptoms which require continuous and palliative care.

However, most of the caregivers are unpaid[12], and in Thai society, they have no bargaining power. Generally, they deliver care under the condition of gratefulness, but may have never prepared themselves for caregiving or have never had experience or knowledge of caring for the elderly beforehand[13]. If the caregivers solely assume the burden of caregiving and any kind of impact, this will eventually lead to an end of caregiving for the elderly in the family and have to make a referral to external agencies to carry out the caregiving[14]. Thus, the elderly will have less chance to live the rest of their lives with their family. Depression in family caregivers comes not only at a great personal cost to their families but also at a substantial financial cost to the society[15].

The elderly's caregivers in the family therefore play an important role in the elderly's good quality of life. While the elderly have been taken good care of, the elderly caregivers should also be recognized for their value and importance. This study aims to examine the correlation between conditions of caring for the elderly and stress of the family caregivers for the sake of fostering collaboration among family members, community and agencies involved to support these family members as caregivers to care for the elderly in the family happily by means of giving any support needed for long-term caregiving for the elderly.

\section{Caregiver stress and burden of care}

Mainly, the term caregiver refers to anyone who provides assistance to someone else, who is, to some degree, incapacitated and needs help. Therefore, caregivers are often responsible for providing physical and emotional support to elderly family members who can limit their ability to participate in regular social activities and decrease their well-being[16]. In addition, the caregiving experiences often lead to multidimensional stressors like physical, psychological, emotional, social and financial depending on the status of the demented recipient[17]. The role of caregiver is associated with negative outcomes for the family caregiver such as health and overall well-being. Moreover, both a longer duration of caregiving and coresidence put the caregiver at risk for more negative outcomes. Then, the accumulation of stress over the course of caregiving may occur[18]. Thus, caregiver stress is the unequal exchange of assistance among people who stand in close relationship to one another, which results in emotional and 
JHR

33,2

140

physical stress on the caregiver. In addition, caregiver stress has also been used to describe the objective and subjective burdens that caregivers face[19].

The degree of burden experienced by caregivers depends on several contextual factors, caregiving-related factors and primary stressors including the socio-demographic status of caregivers and care-recipients, disease progression suffered by the care-recipient and the perceived stress from caregiving. For example, caregivers who advanced in age, women and co-residents experience greater burden than young, male caregivers and those who live apart from care-recipient, and spousal caregivers experience the highest level of burden. Moreover, the functional status of care-recipient, and they independently also affect caregiver burden[20]. Many studies found that most of the caregivers are middle-aged women, being either a daughter or a wife, and likely that their emotional state has changed or been followed by depression[21, 22]. Because women are more vulnerable to burden experience than others, they need specialized support and counseling that address these unique sources of burden[16]. Moreover, informal care for the disabled elderly has proved to be a heavy burden for family caregivers in many countries, and the burden has been shown to be related to the socio-demographic characteristics of both the caregiver and the recipient of care[23]. As same as the elderly with dementia condition, the symptoms might be more severe and become a long-term burden for the caregivers to deliver care to this group of the elderly[24, 25] in the same way as to the elderly with chronic health condition[13, 26]. This may later cause the caregivers' health problem(s)[14]. It could be observed from the higher ratio of this group of caregivers going to consult a specialist about psychological problems than other groups[27], especially those who are getting to suffer from insomnia, feel fatigue from caregiving or have a feeling of a great burden of care are likely to have more stress[28]. Due to health status deterioration and fading memories of the elderly, providing care for this group of recipients is emotionally draining and difficult[15]. Thus, the caregivers may undergo more stress and feel uncomfortable during caregiving than taking care of the general elderly person. In addition, these caregivers have to spare some of their private time and social life to take a close care of the elderly.

Caregiver burden is identified as a state resulting from providing the necessary care to an impaired older adult but that threatens either the physical or psychological well-being of the caregiver[23]. At the same time, it has been defined as the type of stress or strain that caregivers experience related to the problem and challenges they face as a result of the status of care recipient[17]. However, the term caregiver burden has similarities to caregiver stress. Many authors use these two terms interchangeably. The literature seems to present both terms as synonyms of each other[19]. The caregivers with an underlying disease may have more severe symptoms and other health problems after that. Some may even take a more complex role - taking more responsibilities and roles of, for example, parenthood having a burden to take care of their children or their spouse's parents[8]. A burden of caring for the elderly may make the caregivers have less time for recreational activities which also affects the caregivers' mental health[29]. Empirical referents associated with caregiver stress include depression, anxiety, irascibility, disturbances in cognition, decline in physical health and yielding of caring role[19].

In many non-nursing studies related to the stress of the $\mathrm{AD}$ caregiver, the concept of caregiver stress is mostly measured utilizing the Zarit burden scale, while Pearlin et al.'s stress process model (SPM) was also used in non-nursing and nursing articles measuring caregiver stress. A caregiver's role could be in what seems to be stressful. However, if he/she does not perceive his/her situation as stressful, then it is not stressful. Caregiver stress is therefore measured by subjective burden scales because it is perceived by the caregiver[16]. The Zarit Burden Interview (ZBI) was designed to evaluate the challenges that family caregivers of elderly and persons with disabilities face on a daily basis. It contains diverse item content, and takes into consideration both objective and subjective 
burdens experienced by the caregiver[19]. Therefore, in this study, the term caregiver stress will be used similarly with caregiver burden and focused to explain family caregiver stress by using the caregiving SPM, developed by Pearlin et al.[30], as a theoretical framework. Caregiver stress was viewed as a consequence of a process comprising a number of interrelated conditions, including the socioeconomic characteristics and resources of caregivers and primary and secondary stressors to which they are exposed. The onset and progression of chronic illness and functional decline are stressful for both recipient and caregiver and linked to being exposed to a severe, long-term, chronic stressor. The stress process is made up of four domains: the background and context of stress; the stressors; the mediators of stress; and the outcomes or manifestations of stress[15, 30]. The details were as follows.

First, the background and contexts of the stress process refer to socioeconomic status characteristics (such as age, educational level, sex and ethnicity), caregiving history (the relationship of the caregiver to care recipient, quality of the relationship, extent of health problem and duration of caregiving), family and network composition (attachments, structure of the networks and contacts that the caregiver has as a means of support), and program availability (access to community resources that decrease isolation). Second, the stressors common to the caregiving experience are divided into two categories: primary and secondary stressors. Primary stressors are the demands and needs of the care recipients, for example, the impacts of symptoms such as memory loss, communication deficits and recognition failure that accompany the encephalopathy. Secondary stressors are related to the role and intrapsychic strain, which encompass the effects that caregiving has on one's psychological state and on one's ability to work and participate in outside activities. Third, mediating conditions are the mediators which caregivers use to buffer, manage or prevent stress. Coping and social support are considered mediators that determine how caregivers respond to stress and there are two categories of social support, i.e., instrumental and expressive. Finally, outcomes are the last component that involves the consequences and impact of the stress related to the caregiving experience[31].

However, this study did not focus to examine the interrelation between all components, but only used this model to determine the conditions of caring for the elderly which are related to the stress of caregivers. Economic status of caregiver refers to background and contexts of the stress process. Dementia caregiving and economic burden with caring played the role of primary stressors, while confidence of caring and perceived health status of caregiver were secondary stressors, and the relationship between caregiver and care recipient was defined as the mediator of stress. On the other hand, all of these variables were group into conditions of caring for the elderly which related to stress of caregiver in this study and divided into two parts of condition, namely, Readiness of the caregiver which included: health condition, confidence of caring, and economic condition of caregiver; Dependency of the elderly which included: dementia caregiving, relationship between caregiver and care recipient, and economic burden of caring.

\section{Materials and methods}

Study design

This cross-sectional exploratory descriptive research was a part of "Comparison survey on family caregivers of elderly people in Thailand and Japan," which aims to investigate the current situation of family caregivers and to conduct an international comparison survey of family caregivers in Japan and Thailand in order to improve the quality assurance of in-home elderly care, and obtain basic data that can be used for constructing family support systems in both countries through collaboration and applying each country's strengths[32]. 
JHR

33,2

142

\section{Participants}

Participants were the in-home family caregivers for the elderly in the community setting of Chiang Mai Province, Thailand. The sample size was calculated from at least 100 samples by means of calculation of sample size using a formula of $n=10 \mathrm{~K}+50$ ( $\mathrm{K}=$ a number of key variables studied equals to 5 variables)[33]. Simple random sampling was used to collect data from the elderly caregivers in total 103 households where the elderly had been living in. The participants' inclusion criteria consisted of being primary caregivers who were responsible for taking care of the elderly people at home. If in each household, there were more than one elderly person, an elderly recipient who needed the most severe care in the family, for example elderly person with dementia or oldest person, was selected to give their information in the study. However, there were no more than one recipient in each household in this study because, in general, if there are a couple of elderly persons who were spouse, one would take the role of caregiver while another as a recipient, or the oldest elderly would be a recipient while the younger was a caregiver.

\section{Study area}

The community area in Chiang Mai Province was chosen to be the study area as it has been the most populated province in the north; 16.8 percent of the entire population was the elderly. The population of the elderly in 2016 was 5.1 percent higher than that in 2015[34], and aging index was considered high at 90.5 in 2013 and expected to increase to 160.27 in 2020[1]. The area of Ban Klang Subdistrict, San Pa Tong District was chosen to be the study area by using purposive sampling.

\section{Data collection and instruments}

Data collection was carried out from April to November 2016 by a structured interview via a questionnaire, and took place in the caregiver's home. The questionnaire was developed by key researchers from Graduate School of Health Sciences, Kobe University. It was translated into Thai and adjusted to suit Thai community contexts and examined for content validity by three experts who were community health nurse, a nurse gerontologist, and public health personnel. The questionnaire covered characteristics of participants (family caregivers and care recipients); care burden; support in caring; emotional effect and training in caring of the elderly; opinion in taking care of the elderly; and motivation to continue caregiving of care receivers.

Family caregiver stress was measured by using the eight-item short version of the ZBI, which is proposed with the following two factors: Personal strain (five item) and Role strain (three items)[35]. Response to each item was rated on a 0-4 scale: $0=$ "never," $1=$ "rarely," $2=$ "sometimes," $3=$ "quite frequently," and $4=$ "nearly always." Higher scores reflect more severe care burdens or high stress. The scores were calculated by summing all items and ranged from 0 to 32. The scores of 0 indicate "no burden or stress", 1-10 "mild or little stress," 11-20 "moderate stress" and 21-32 indicating "severe burden or high stress." A pilot study was conducted with 30 family caregivers with similar characteristics of the sample and the Cronbach's alpha coefficient of the eight-item ZBI was 0.86 .

\section{Data analysis}

Data were analyzed via descriptive statistics and the $\chi^{2}$ test. Descriptive statistics including frequency, percentage, mean and standard deviation were used to analyze basic information related to the status of the elderly caregivers in the family. Bivariate analysis using the $\chi^{2}$ test was used to explore the correlation between conditions of caring and stress among family caregiver. 
Ethical consideration

Ethical approval for the research instrument had been obtained from Institutional Review Board of the Graduate School of Health Sciences, Kobe University, Japan (Reference Number: 452-1), which was approved on March 17, 2016. The Faculty of Nursing, Chiang Mai University recognized this consideration. All participants were given information about the research project and could terminate the participation when they feel unsatisfied with the situation. All the results were shown, only the outcomes of the study and the name or private information of participants were kept confidential.

\section{Results}

The findings were divided into the following four parts: characteristics of the elderly caregivers and the elderly; situations of caring for the elderly; conditions of caring for the elderly and level of stress; and the relationship between conditions of caring and perceived stress as being the elderly caregivers.

\section{Characteristics of the elderly caregiver and the elderly}

Out of 103 caregivers, two-thirds of them were mostly women (73.8 percent) at the average age of 49. Nearly, one-fourth of them were the elderly (20.3 percent), and half of them got married (55.3 percent). Considering the economic status of the elderly caregivers in the community, almost 79.6 percent were still working and had their own earned income (Table I).

Considering the general characteristics of the elderly recipient, female elderly were slightly more than male, average age at 77 , and more than 40 percent were over 80 years old. Most of them were the caregivers' parents (64.1 percent) and were in the state of considerable to great need of care and assistance (70-100 percent). A small number of them were able to help themselves or needed limited assistance (less than 50 percent assistance) (Table II).

Situation of family caregiver in caring for the elderly

It was noticeable that a large number of the caregivers (56.3 percent) in this study stated that they did not prepare themselves beforehand for taking care of the elderly. Most of them

\begin{tabular}{|c|c|c|c|}
\hline Characteristic & $n$ & $\%$ & \\
\hline \multicolumn{4}{|l|}{ Gender } \\
\hline Male & 27 & 26.2 & \\
\hline Female & 76 & 73.8 & \\
\hline \multicolumn{4}{|l|}{ Age (years) } \\
\hline$<30$ & 9 & 8.8 & \\
\hline $30-39$ & 17 & 16.5 & \\
\hline $40-49$ & 22 & 21.4 & \\
\hline $50-59$ & 34 & 33.0 & \\
\hline $60-69$ & 16 & 15.5 & \\
\hline$\geqslant 70$ & 5 & 4.8 & \\
\hline \multicolumn{4}{|l|}{ Marital status } \\
\hline Married & 57 & 55.3 & \\
\hline Single & 38 & 36.9 & \\
\hline Divorced/separated & 8 & 7.8 & \\
\hline \multicolumn{4}{|l|}{ Employment status } \\
\hline Continued to work & 82 & 79.6 & \\
\hline Do not work & 21 & 20.4 & Characteristics of \\
\hline Notes: $n=103$. Mean $=49.1 ; \mathrm{SD}=13.3$ & & & family caregiver \\
\hline
\end{tabular}

Elderly and family caregiver stress

143 
Gender

Male

$\begin{array}{ll} & \text { Age (years) } \\ \mathbf{1 4 4} & 60-69\end{array}$

70-79

80-89

$\geqslant 90$

Generational relationship

Spouse

Parent

Grandparent and other relatives

Level of assistance

Notes: $n=103$. Mean $=77.1 ; \mathrm{SD}=9.5$

(70.8 percent) stated that they had never received any training on caregiving for the elderly, and almost half of them (45.6 percent) had never searched for any information regarding caregiving for the elderly before. One-third of the caregivers stated that they had no consultant in caregiving for the elderly. However, family members had been a core supporter of caregiving for the elderly and other assistance in the form of emotional support from friends, acquaintances, and religious organization(s). Most of them had financial support or assistance from public agencies or organizations, especially from subsistence allowance, and some from their kin, whereas some caregivers (17.5 percent) stated that they did not receive any financial support from any resource (Table III).

\section{Conditions of caring for the elderly and stress of family caregiver}

The conditions of caring for the elderly in this study were divided into two factors: Readiness of the caregiver in terms of health status, confidence of care and the economic status of the caregivers; and Dependency of caring such as dementia caregiving, the relationship between the caregiver and the elderly, and the economic burden of care. The details are shown in Table IV.

Readiness of the caregiver. Considering the caregivers' perceived well-being, approximately 53.3 percent evaluated themselves that their health condition, in general, was rather good. Moreover, half of the caregivers (53.3 percent) stated that they were extremely confident in assuming a burden of caring for the elderly. Though the rest of them had no work, only some of them (8.7 percent) felt they had run into economic difficulty.

Dependency of the elderly. Half of the elderly in the family (49.5 percent) suffered from dementia or faded memory. However, the relationship between the caregivers and the elderly was very good (73.8) and quite good (15.5 percent). Regarding the economic burden from taking care of the elderly, one-third of the caregivers (34.9 percent) stated that it was a heavy burden for them, while the others thought that it was quite some burden in a similar proportion (34 percent). On the other hand, some of the caregivers (31.1 percent) thought that caring for the elderly was not their economic burden. 


\begin{tabular}{|c|c|c|c|}
\hline Characteristic & $n$ & $\%$ & $\begin{array}{l}\text { Elderly and } \\
\text { family }\end{array}$ \\
\hline $\begin{array}{l}\text { Preparation for elderly caring } \\
\text { Never prepare } \\
\text { A little } \\
\text { Very much }\end{array}$ & $\begin{array}{l}58 \\
23 \\
22\end{array}$ & $\begin{array}{l}56.3 \\
22.3 \\
21.4\end{array}$ & $\begin{array}{r}\text { caregiver } \\
\text { stress }\end{array}$ \\
\hline $\begin{array}{l}\text { Training } \\
\text { Not received } \\
\text { Received }\end{array}$ & $\begin{array}{l}73 \\
30\end{array}$ & $\begin{array}{l}70.8 \\
29.3\end{array}$ & 145 \\
\hline $\begin{array}{l}\text { Information seeking } \\
\text { No } \\
\text { Yes }\end{array}$ & $\begin{array}{l}47 \\
56\end{array}$ & $\begin{array}{l}45.6 \\
54.4\end{array}$ & \\
\hline $\begin{array}{l}\text { Advisor } \\
\text { No } \\
\text { Yes }\end{array}$ & $\begin{array}{l}37 \\
66\end{array}$ & $\begin{array}{l}35.9 \\
64.1\end{array}$ & \\
\hline $\begin{array}{l}\text { Supporter } \\
\text { None } \\
\text { Family } \\
\text { Friend } \\
\text { Religion }\end{array}$ & $\begin{array}{r}3 \\
87 \\
11 \\
2\end{array}$ & $\begin{array}{r}2.9 \\
84.5 \\
10.7 \\
1.9\end{array}$ & \\
\hline $\begin{array}{l}\text { Financial support } \\
\text { Not received } \\
\text { Received from a public agency } \\
\text { Received from relatives } \\
\text { Note: } n=103\end{array}$ & $\begin{array}{l}18 \\
68 \\
17\end{array}$ & $\begin{array}{l}17.5 \\
66.0 \\
16.5\end{array}$ & $\begin{array}{r}\text { Table III. } \\
\text { Situation of family } \\
\text { caregiver in caring for } \\
\text { the elderly }\end{array}$ \\
\hline
\end{tabular}

Perceived stress of family caregiver. As a whole, the caregivers had positive attitude toward caregiving for the elderly in the family, but at the same time, underwent stress as taking a role of a caregiver which was something they could not avoid. The caregivers reported a varied degree of stress with a mean of 6.6. The majority of them (74.8 percent) experienced none or little stress, while some of them (21.4 percent) felt moderate stress in caring of the elderly and only 3.9 percent perceived high stress.

The relationship between conditions of caring and stress of the caregivers

Considering the conditions probably assumed to correlate with the caregivers' stress using the $\chi^{2}$ test, it was found that the conditions related to the perceived stress of caregivers were health status, confidence of caring, the relationship between the caregiver and the elderly, and the economic burden of care. The details are shown in Table V.

Readiness of the caregiver. It was likely that a group of caregivers with good health condition was likely to have less stress than other groups $(p=0.003)$. Moreover, the caregivers with high confidence in caring for the elderly were likely to have less stress than those with less confidence $(p=0.000)$. However, the economic status of caregivers did not have a significant relationship with the stress of caregivers.

Dependency of the elderly in the family. It was obviously seen that if there was a good relationship between the caregivers and the elderly, the caregivers were likely to have less perceived stress $(p=0.000)$. In addition, if the caregivers did not feel that caring for the elderly was such a substantial economic burden for them, they were likely to have less stress $(p=0.000)$. However, the elderly with dementia did not find to have a significant relationship with caregiver stress in this study. 
1. Readiness of caregiver

Health condition

Unhealthy/slightly unhealthy $\quad 8 \quad 10.7$

Neither good or bad $\quad 18 \quad 36.0$

$1462 \begin{gathered}\text { Slightly healthy } \\ \text { Confidence of caring }\end{gathered}$

Not so much or little $\quad 48 \quad 46.7$

Very much $\quad 55 \quad 53.3$

$\begin{array}{lcc}\text { Economic status } & 9 & 8.7 \\ \text { Strained } & 9 & 65.1\end{array}$

$\begin{array}{lrr}\text { Normal } & 37 & 65.1\end{array}$

$\begin{array}{lll}\text { Comfortable } & 27 & 26.2\end{array}$

2. Dependency of caring

Dementia caregiving

Yes

49.5

$\begin{array}{lrr}\text { No } & 52 & 50.5\end{array}$

$\begin{array}{lll}\text { Relationship } & 76 & 73.8\end{array}$

$\begin{array}{lll}\text { Good } & 16 & 15.8 \\ \text { Good } & 16 & 10.5\end{array}$

$\begin{array}{lll}\text { Not particularly good } & 11 & 10.7\end{array}$

$\begin{array}{lll}\text { Economic burden } & 36 & 34.9\end{array}$

$\begin{array}{lll}\text { Some burden } & 35 & 34.0\end{array}$

Do not feel any burden $\quad 32 \quad 31.1$

3. Stress

Perceived stress

$\begin{array}{lll}\text { None or little stress } & 77 & 74.8\end{array}$

$\begin{array}{llrr}\text { Table IV. } & \text { Moderate stress } & 22 & 21.4 \\ \text { Conditions of caring } & \text { High stress } & 4 & 3.9\end{array}$

Notes: $n=103$. Mean $=6.6$; $\mathrm{SD}=5.8$

\section{Discussion}

Declining fertility transformed the extended families from an average of five members per household to only three persons at present and leads to the increasing proportion of elderly who are living alone or with only their elderly spouse. The type of elderly domicile is also affected by the economic status of the family. One-thirds of the elderly were living in households with income below the poverty line and the elderly who received economic support from their child(ren) had declined[2]. Therefore, a burden of caring for the elderly becomes a duty of other younger elderly in the same household. It might be that most of the elderly's descendants must take a burden of earning income economically and the younger elderly in the family not only have to take care of themselves but also care for other elderly in household who need more care. However, according to traditional family practice, most of the caregiving for the elderly in household has been a burden of female caregivers, especially single, holding a status as a daughter or a wife[21]. Nevertheless, considering the ratio presented in this study, men are likely to care for the elderly substantially when compared with past practice, showing that the burden of care in several aspects fell solely on women.

In addition, it can be seen that caring for the elderly in the family mainly done by descendants by bloodline or by spouse creates a bond between the caregivers and the elderly, thus resulting in a good relationship between them although the elderly are in need 


\begin{tabular}{|c|c|c|c|c|c|}
\hline \multirow[b]{2}{*}{ Conditions } & \multicolumn{3}{|c|}{ Perceived stress $n(\%)$} & \multirow[b]{2}{*}{$p$-value } & Elderly and \\
\hline & None or little stress & Moderate stress & High stress & & tamily \\
\hline \multicolumn{5}{|l|}{ 1. Readiness of the caregiver } & r \\
\hline Health condition & & & & $0.003^{*}$ & stress \\
\hline Unhealthy/slightly unhealthy & $4(50.0)$ & $3(37.5)$ & $1(12.5)$ & & \\
\hline Neither good or bad & $10(55.6)$ & $5(27.8)$ & $3(16.7)$ & & \\
\hline Slightly healthy & $63(81.8)$ & 14 (18.2) & $0(0.0)$ & \multirow{4}{*}{$0.000^{*}$} & 147 \\
\hline \multicolumn{4}{|l|}{ Confidence of caring } & & \\
\hline Not so much or little & $26(54.2)$ & 18 (37.5) & $4(8.3)$ & & \\
\hline Very much & $51(92.7)$ & $4(7.3)$ & $0(0.0)$ & & \\
\hline \multicolumn{4}{|l|}{ Economic condition } & \multirow[t]{4}{*}{0.591} & \\
\hline Strained & $6(66.7)$ & $2(22.2)$ & $1(11.1)$ & & \\
\hline Normal & $51(76.1)$ & $13(19.4)$ & $3(4.5)$ & & \\
\hline Comfortable & $20(74.1)$ & $7(25.9)$ & $0(0.0)$ & & \\
\hline \multirow{2}{*}{\multicolumn{4}{|c|}{$\begin{array}{l}\text { 2. Dependency of the elderly } \\
\text { Elderly having dementia }\end{array}$}} & \multirow{4}{*}{0.159} & \\
\hline & & & & & \\
\hline Yes & $34(66.7)$ & 14 (27.5) & $3(5.9)$ & & \\
\hline No & $43(82.7)$ & 8 (15.4) & $1(1.9)$ & & \\
\hline \multicolumn{4}{|l|}{ Relationship condition } & \multirow[t]{4}{*}{$0.000^{*}$} & \\
\hline Very good & $65(85.5)$ & $11(14.5)$ & $0(0.0)$ & & \\
\hline Good & $9(56.3)$ & $7(43.8)$ & $0(0.0)$ & & \\
\hline Not particularly good & $3(27.3)$ & $4(36.4)$ & $4(36.4)$ & & \\
\hline \multicolumn{4}{|l|}{ Economic burden } & \multirow[t]{5}{*}{$0.000^{*}$} & Table V. \\
\hline Very heavy/some & $18(50.0)$ & $14(38.9)$ & $4(11.1)$ & & Relationship between \\
\hline Not feel much & $30(85.7)$ & $5(14.3)$ & $0(0.0)$ & & conditions of caring \\
\hline Not much & $29(90.0)$ & $3(9.4)$ & $0(0.0)$ & & and perceived stress \\
\hline \multicolumn{4}{|l|}{ Note: $*$ Significance level $\alpha=0.05$} & & of family caregivers \\
\hline
\end{tabular}

of intensive care or have communication problems. This is the reason why the relationship between caregivers and the elderly recipient played an important role to reduce or relieve stress among caregiving in this study, while the severity of behavioral problems like the elderly recipient with dementia was not associated with higher levels of caregiver stress[36]. Even though all these caregivers are not quite ready or well prepared for such a burden or for body of knowledge or for information regarding caregiving for the elderly, they still want and are willing to care for the elderly in the family because of the bonds between them as well as value of gratefulness which is the root in Thai society[6] and has been adhered to and observed within the community.

Most of the caregivers feel that caring for the elderly in household does not affect or create economic difficulty, partly because they are still able to earn income. Moreover, they have received a subsidy from external agencies or their kin, especially when they are also the elderly. Some of the caregivers not only earn their own income but also get subsistence allowance for themselves and for the elderly under care, thus making them feel that caregiving is not a great burden. However, the findings have revealed that the feeling of economic burden affects the feeling of stress for being a caregiver because each caregiver is in a different state of readiness for resources in caregiving for the elderly. Mostly, they are unpaid caregivers[13].

In the same way as for readiness of the caregivers' health, most of the caregivers feel that they are still in good health and likely to be ready for caring for the elderly. However, it is likely that such readiness correlates with the stress in caregiving. It is also possible that some illnesses may occur during the period of caring for the elderly[14]. Moreover, the caregivers may feel that their health status may have an impact on their potential for caring 
JHR

33,2

148

for the elderly because they have to take care of their own health at the same time. Nevertheless, this may be because if the caregiver perceived they have good health, they still enjoy their social life as necessary and do not have the feeling that caring for the elderly is a burden distracting them from social life. It is also another way to relieve their stress, and so, they are able to retain their privacy[29]. However, when compared to elderly caregivers in Japan, the condition of family caregivers was better in Thailand than in Japan. Despite there being a long-term care insurance system in Japan and not Thailand, Thai caregivers felt a lighter care burden and less loneliness, which relate to family caregivers in Thailand having more social connections and informal support than those in Japan[32]. All these are necessary for the work of caregiving for the elderly in the community that requires support at both the individual and community levels. Moreover, necessary resources in other aspects to help support and boost more confidence of these caregivers as well as an increase of capacity of the family in caring for the elderly[8] are extremely significant that family members, community, and society should place an importance on, because by doing so, it will not only lessen stress in being a caregiver but also help make the elderly be taken good and great care of by family members.

\section{Recommendations}

To reduce the stress of the elderly caregivers, readiness at an individual level and at the community level is required to support the caregivers in the family. This is because the caregivers with high confidence in caring for the elderly are likely to have less stress, and giving resources to enhance the confidence of caregivers is very important. Resources that will help strengthen confidence in caregiving may be in the form of materials, body of knowledge and enhancing mental stability. Furthermore, what the caregivers require most are additional knowledge, understanding or training in caregiving for the elderly properly in order to boost their confidence in caring for the elderly. In addition, the stress of caregivers can be decreased by reducing the caregivers' economic burden in addition to subsistence allowance received on a regular basis through activities that increase the caregivers' income, whereas they can still care for the elderly at home at the same time.

In order to relieve caregivers' stress and improve the capacity of the elderly, it is necessary to create a system of long-term care operating by the community and collaboration among the community or a network of the family caregivers to build social support, understanding and exchange of experiences in caregiving as well as an emergency assistance system in the community in case that transfer of the elderly or urgent help is required.

\section{References}

1. Office of the Permanent Secretary, Ministry of Social Development and Human Security. Thai ageing population: now and future. Bangkok: Information Technology and Communication Center, Ministry of Social Development and Human Security; 2014.

2. Foundation of Thai Gerontology Research and Development Institute (TGRI). Situation of the Thai elderly 2015. Bangkok: Amarin Printing; 2017.

3. Szplit A, Chabior A, Quero S, Pérez-Ara MÁ, Biggio G. A new senior caregiver for a new millennium - the EduCare project. Procedia - Soc Behav Sci. 2014; 141(1): 1254-58.

4. The Secretariat of the Senate. Synthesis of caring for the elderly in Thailand: problems and suggestions. Bangkok: The National Legislative Assembly; 2016.

5. Shrestha B, Sermsri S, Hongkrailert N. Self-efficacy, family support and physical-social functioning activity among Thai elderly under a community QOL program, Kanchanaburi province. Thailand J Pub Health Dev. 2012; 10(3): 3-15. 
6. Srithamrongsawat S, Bundhamcharoen K. Synthesis of long-term care system for the Elderly in Thailand. Bangkok: Foundation of Thai Gerontology Research and Development Institute; 2010.

7. Vongchavalitkul B, Sanguanwongwan W, Chatchaisucha S, Limsarun T, Thaisamak S, Ruengkhajhon K. Knowledge and attitude of the Elderly Caregivers: a case study of Thammapakorn Phoklang and Watmuang Elderly Care Center Nakhonratchasima Province. J Bus Adm. 2016; 5(2): 74-92.

8. Yodpet S. Elderly caregiver in the family. Proceeding of Caring System and Labor Force in Elderly Caregiving, Oct 30; Bangkok: Chulabhorn Research Institute Convention Center; 2008. 1-9.

Elderly and family caregiver stress

9. Wasilewskia MB, Stinsonb JN, Camerona JI. Web-based health interventions for family caregivers of elderly individuals: a scoping review. Int J Med Eng Informat. 2017; 103(1): 109-38.

10. Winahyu KM, Hemchayat M, Charoensuk S. Factors affecting quality of life among family caregivers of patients with schizophrenia in Indonesia. J Health Res. 2015; 29(1): 77-82.

11. Yodpet S. Family and the elderly. Vichawut C, et al. Editors. Review and synthesis of Thai elderly knowledge, 2002-2007: a research plan for improving the quality of life of the Elderly. Bangkok: Foundation of Thai Gerontology Research and Development Institute; 2009. 193-226.

12. Sihapark S, Chuengsatiansup K, Tengrang K. The effects and caregiving burdens of older persons in long-term care based on Thai culture. Nonthaburi: Society and Health Institute; 2014.

13. Tao H, McRoy S. Caring for and keeping the elderly in their homes. Chin Nurs Res. 2015; 2(2-3): 31-4.

14. Schoenmakers B, Buntinx F, Delepeleire J. Factors determining the impact of care-giving on caregivers of elderly patients with dementia. A systematic literature review. Maturitas. 2010; 66(2): 191-200.

15. Lavretsky H. Stress and depression in informal family caregivers of patients with Alzheimers disease. Aging Health. 2005; 1(1): 117-33.

16. Elsa V. Informal family caregiver burden in elderly assistance and nursing implications. Ann Nurs Pract. 2015; 2(1): 1017-19.

17. Jaisri M. Caregiver burden and depression among dementia caregivers. Int J Soc Sci Humanit Res. 2014; 2(4): 365-71.

18. Hoyert DL, Seltzer MM. Factors related to the well-being and life activities of family caregivers. Family Relations: Interdiscipl J Appl Fam Stud. 1992; 41(1): 74-81.

19. Llanque S, Savage L, Rosenburg N, Caserta M. Concept analysis: Alzheimer's caregiver Stress. Nurs Forum 2016; 51(1): 21-31.

20. Kim H, Chang M, Rose K, Kim S. Predictors of caregiver burden in caregivers of individuals with dementia. J Adv Nurs. 2012; 68(4): 846-55.

21. Rezende TC, Coimbra AM, Costallat LT, Coimbra IB. Factors of high impacts on the life of caregivers of disabled elderly. Arch Gerontol Geriatr 2010; 51(1): 76-80.

22. Rezende G, Gomes CA, Rugno FC, Eva G, Lima NKC, De Carlo MMRP. Burden on family caregivers of the elderly in oncologic palliative care. Eur Geriatr Med. 2017; 8(4): 337-41.

23. Salama RAA, Abopu El-Soud FA. Caregiver burden from caring for impaired elderly: a cross-sectional study in rural Lower Egypt. Ital J Public Health. 2012; 9(4): 1-10.

24. Chen HM, Hou SY, Yeh YC, Chang CY, Yen JY, Ko CH, et al. Frontal function, disability and caregiver burden in elderly patients with major depressive disorder. J Med Sci. 2010; 26(10): 548-54.

25. Hirakawa Y, Kuzuya M, Enoki H, Hasegawa J, Iguch A. Caregiver burden among Japanese informal caregivers of cognitively impaired elderly in community settings. Arch Gerontol Geriatr. 2008; 46(3): 367-74.

26. Mahdavi B, Fallahi-Khoshknab M, Mohammadi F, Hosseini MA, Haghi M. Effects of spiritual group therapy on caregiver strain in home caregivers of the elderly with Alzheimer's disease. Arch Psychiatr Nurs. 2017; 31(3): 269-73. 
27. Baumgarten M, Battista RN, Infante-Rivard C, Hanley JA, Becker R, Bilker WB, et al. Use of physician services among family caregivers of elderly persons with dementia. J Clin Epidemiol. 1997; 50(11): 1265-72.

28. Luchesi BM, Souza ÉN, Gratão AC, Gomes GA, Inouye K, Alexandre Tda S, et al. The evaluation of perceived stress and associated factors in elderly caregivers. Arch Gerontol Geriatr. 2016; 67(1): 7-13.

29. Losada A, Pérez-Peñaranda A, Rodriguez-Sanchez E, Gomez-Marcos MA, Ballesteros-Rios C, Ramos-Carrera IR, et al. Leisure and distress in caregivers for elderly patients. Arch Gerontol Geriatr. 2010; 50(3): 347-50.

30. Pearlin LI, Mullan JT, Semple SJ, Skaff MM. Caregiving and the stress process: an overview of concepts and their measures. Gerontologist. 1990; 30(5): 583-94.

31. Bolden L, Wicks MN. The clinical utility of the Stress Process Model in family caregivers of liver transplant candidates. Prog Transplant. 2008;18(2): 74-9.

32. Greiner C., Tamdee D., Okamoto N, Tamdee P, Isowa T, Booonchiang W, et al. Comparison Survey on Family Caregivers of Elderly People in Japan and Thailand. Innov Aging. 2017; 1(S1): 601.

33. Thorndike RL. Stability of factor loadings. Person Individ Diff. 1987; 8(4): 585-6.

34. Chiang Mai Provincial Statistical Office. Strategic Issues Analysis: society and Potential products: the elderly people. 2017; 1-4. [updated: 2017 Dec 25; cited 2018 Mar 2]. Available from: http://164. 115.25.139/mischm2018/analysis/6_Analyze_elderly.pdf

35. Arai Y, Tamiya N, Yano E. The short version of the Japanese version of the Zarit caregiver burden interview (J-ZBI_8): its reliability and validity. Nihon Ronen Igakkai Zasshi. 2003; 40(5): 497-503.

36. Zarit SH, Reever KE, Bach-Peterson J. Relatives of the impaired elderly: correlates of feelings of burden. Gerontologist. 1980; 20(6): 649-55.

\section{Corresponding author}

Patrapan Tamdee can be contacted at: fsocppl@ku.ac.th

For instructions on how to order reprints of this article, please visit our website: 